
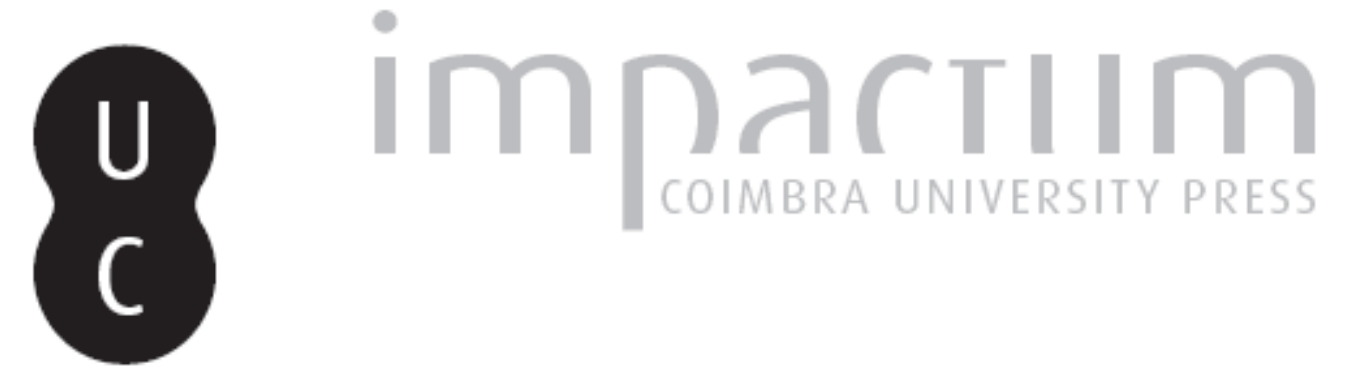

\title{
Um apito anelar romano de Conímbriga
}

\author{
Autor(es): Pessoa, Miguel
}

Publicado por: Imprensa da Universidade de Coimbra

URL persistente:

URI:http://hdl.handle.net/10316.2/45434

DOI:

DOI:https://dx.doi.org/10.14195/1647-8657_36_9

Accessed : $\quad$ 26-Apr-2023 11:33:16

A navegação consulta e descarregamento dos títulos inseridos nas Bibliotecas Digitais UC Digitalis, UC Pombalina e UC Impactum, pressupõem a aceitação plena e sem reservas dos Termos e Condições de Uso destas Bibliotecas Digitais, disponíveis em https://digitalis.uc.pt/pt-pt/termos.

Conforme exposto nos referidos Termos e Condições de Uso, o descarregamento de títulos de acesso restrito requer uma licença válida de autorização devendo o utilizador aceder ao(s) documento(s) a partir de um endereço de IP da instituição detentora da supramencionada licença.

Ao utilizador é apenas permitido o descarregamento para uso pessoal, pelo que o emprego do(s) título(s) descarregado(s) para outro fim, designadamente comercial, carece de autorização do respetivo autor ou editor da obra.

Na medida em que todas as obras da UC Digitalis se encontram protegidas pelo Código do Direito de Autor e Direitos Conexos e demais legislação aplicável, toda a cópia, parcial ou total, deste documento, nos casos em que é legalmente admitida, deverá conter ou fazer-se acompanhar por este aviso.

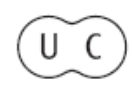


UNIVERSIDADE DE COIMBRA

FACULDADE DE LETRAS

\section{CONIMBRIGA}

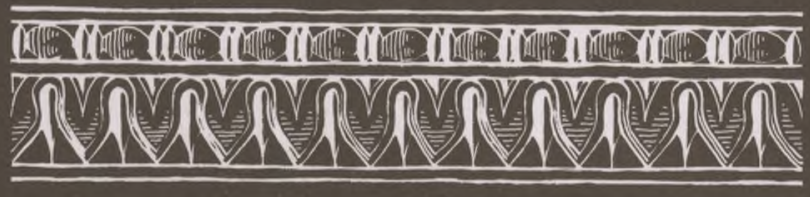

VOLUME XXXVI - 1997 
Miguel Pessoa

Conservador do Museu Monográfico de Conimbriga

\section{UM APITO ANELAR ROMANO DE CONIMBRIGA}

"Conimbriga" XXXVI (1997) p. 165-175

RESUMO: O apito anelar romano que aqui se apresenta é formado por duas partes: tubo sonoro e anel de suspensão. O corpo do tubo está dividido transversalmente em três partes distintas, conjugando a representação de elementos do equipamento militar do oficial romano com a organologia do instrumento.

Foi descoberto a escassas centenas de metros da porta da muralha do Alto Império que dá saída para Aeminium, no núcleo populacional actual da Vaiada; balate ou al-balate significa em árabe «a via, a calçada, a estrada».

Os subúrbios de Conimbriga eram, à semelhança do que acontece nas cidades actuais, habitados por uma população que vivia em construções precárias aproveitando sobretudo as áreas livres ao longo das estradas principais. Estas eram igualmente espaços privilegiados para a instalação temporária de contingentes militares.

RÉSUMÉ: Le sifflet à bague romain ici présenté est formé par deux parties: un tuyau sonore et l'anneau de suspension. Le corps du tuyau est divisé transversalment en trois différents parties. Elles représentent d'une part les éléments de l'équipement militaire de l'officier romain et d'autre part les différents parties techniques de l'instrument.

Il a été découvert à quelques centaines de mètres de la porte de l'enceinte Haute Empire de Conimbriga en sortant pour Aeminium, dans l'actuelle agglomération de Valada. Balate ou al-balate signifie en langue arabe «la voie, rue pavée, route».

La banlieue de Conimbriga était, comme aujourd'hui dans quelques villes actuelles, habitée par une population occupant des habitations modestes. Elles s'installaient aux abords des routes, là où souvent les contingents militaires prennaient place temporairement.

Conimbriga, 36 (1997) 165-175 
(Página deixada propositadamente em branco) 


\section{A DESCOBERTA DE UM APITO ANELAR ROMANO DE CONIMBRIGA}

\section{Introdução}

O apito anelar que agora se apresenta foi recolhido na década de sessenta, nos subúrbios de Conimbriga (Estampa I).

Embora esta recolha resulte de um achado fortuito (PESSOA, 1986, p. 62) e careça de elementos que melhor a informem, não pode considerar-se um testemunho "errático" dado que foi garantida a sua localização 0). Faltam-nos, porém, alguns elementos fundamentais que acompanham uma recolha "sistemática" em contexto arqueológico - dados estratigráfícos, localização de pormenor em planta a uma escala adequada, registo de estruturas associadas e de materiais datáveis.

A localização do achado no aglomerado populacional de Vaiada (Estampa II - Fotografia 1) evidencia-nos dois aspectos que nos parecem indissociáveis. Este local encontra-se a cerca de seis centenas de metros da porta da muralha do Alto Império, que dá saída para Aeminium (PESSOA, 1991, p. 25-27), no prolongamento da via romana e no alinhamento do "decumanus", com direcção nordeste - sudoeste, cujo enfiamento toca o sul do forum da cidade (ALARCÃO, 1977, p. 17, 23-25). Ao longo deste trajecto provável da via romana, no exterior da cidade, foram já detectados vestígios duma necrópole (OLEIRO, 1952, p. 32-42), paredes, canalizações $\left({ }^{2}\right)$ e materiais de construção, de que

P) $\mathrm{O}$ achado ocorreu durante a abertura de caboucos para a adução de águas domiciliares numa casa de habitação sita no lado sul do Largo de Santo António, na entrada poente da localidade de Vaiada, Freguesia de Condeixa-a-Velha, Concelho de Condeixa-a-Nova.

Coordenadas Militares: 169,95; 348,65. Folha 251, escala 1: 25.000, Serviços Cartográficos do Exército, Trabalhos de Campo de 1947.

${ }^{(2)}$ Estruturas detectadas pelo revolvimento de terras durante trabalhos agrícolas 
são exemplo muito actual os testemunhos por nós detectados e relatados durante os recentes trabalhos de construção da variante de Tomar que rompe os espaços dos subúrbios da cidade.

O segundo aspecto que nos parece indissociável é o que está relacionado com o topónimo Vaiada e a sua provável origem. Balate ou al-balate significa em língua árabe ( $\left.{ }^{3}\right)$ «a via, a calçada, a estrada» (ALARCÃO, 1988, p. 45). A semelhança com a palavra actual não nos parece ocasional podendo, assim, indiciar que a via medieval (e provavelmente, a romana) passava por esse lugar.

\section{Forma e concepção}

A observação realizada quer a olho nu, quer através da lupa binocular com luz rasante, revelou-nos uma textura de liga metálica oxidada nalgumas zonas, com um tipo de alteração própria da liga de estanho e chumbo. Trata-se duma peça fundida com vazamento num molde bivalve. O núcleo ou contramolde que ocupava todo o corpo do tubo estava ligado a uma das valvas ou estaria equilibrado ou suspenso na zona da embocadura? Seria a peça após a fundição aberta depois por furação com broca? E por outro lado bem visível a linha de contacto entre as duas metades do molde que deixou bem à vista a rebarba de metal que passou para além do interior esculpido $\left(^{4}\right)$. Esta baba, rebarba ou ganga é bem visível numa linha mediana que liga a embocadura à

e aquando da abertura de fundações para a instalação de postes de electricidade dentro e fora da subestação da EDP.

${ }^{(3)}$ Existe em Conimbriga, dessa época, mais de uma dezena de espécimes numismáticos em prata (Dirham) e em bronze (Fais) datados dos séculos VIII e IX, exemplares estes provenientes do Califado Omíada de Damasco e do Emirato andaluz (MARINHO, 1974, p.313-314).

Muitos dos traçados viários antigos mantiveram-se ao longo da história. Outros ficaram gravados na memória dos espaços conferindo-lhe valor cultural (BERNFELD, 1993/1, p.33-34).

${ }^{(4)}$ Encontram-se em exposição permanente no Museu de Conimbriga vários exemplares de moldes bivalves em cerâmica, provenientes quer das escavações de Vergilio Correia (MoutinHo ALARCÃO, 1994, n. ${ }^{\circ} 122$ e 123) quer das escavações luso -francesas (ALARCÃO, 1979, p. 203, n. ${ }^{\circ}$ 381-383). A existência nestacolecção de algumas peças fundidas mostrando o jito e as rebarbas, moldes de vários tipos, cadinhos e algaravizes demonstram-nos com evidência a prática corrente desta metalurgia.

Conimbriga, 36 (1997) 165-175 
boca, elmo, crista e linha interior e exterior do aro circular do anel. Este está partido na zona de contacto com a parte anterior da crista do elmo. A alma do apito foi fundida à parte e posteriormente embutida. A sua fixação, após afinação, foi feita com a dobragem de dois grampos (um partido), fundidos no molde, presentes dum lado e do outro da entrada do canal da embocadura. A natureza dúctil desta liga metálica permitiu cortes de acerto e acabamento visíveis na boca, tacão ou alma e canal do ar (Fotos 1 e 2).

A análise da composição elementar através das técnicas de microscopia electrónica de varrimento e de microanálise por raios X- SEM/EDS (SÁ, 1996) foi realizada com o fim de conhecer a composição química da peça propriamente dita e de nos certificar se não estaríamos perante um falso. Trata-se de um método não destrutivo que garante, ao contrário da análise convencional, a total integridade da peça, permitindo, ainda, a observação ao microscópio das zonas analisadas. A composição do metal analisado corresponde à de uma liga de estanho e chumbo (teor elevado em estanho 64, 49\%, contendo menores quantidades em chumbo 35, 51\%) bem como os traços habituais das ligas de estanho e chumbo (Estampa IV) ${ }^{(5)}$. Esta composição é homogénea e corrobora as observações feitas a partir dos documentos radiográficos convencionais) ${ }^{6}$ ). Pode servir de elemento precioso de comparação com outros dados (EVIN, 1990) e complementado com uma análise isotópica (LARANJEIRA, 1968, p. 55-56).

A peça apresenta duas partes distintas: tubo sonoro e anel de suspensão (Estampa III). A primeira lembra uma mesa de anel unida ao aro no bloco original do molde de fundição. Esta mesa tem forma tubular

$\left(^{5}\right)$ A análise realizada junto ao orifício do bocal revelou um aumento da percentagem do estanho e uma enorme diminuição da presença do chumbo. Tal facto explicate pelo desgaste provocado pelo uso do objecto como instrumento sonoro.

$\left.{ }^{6}\right)$ As radiografias convencionais realizadas destinaram-se a fazer aparecer a estrutura interna do apito. Foram realizadas, por duas vezes, a uma distância focal de um metro com raios $\mathrm{X}$ duros. A placa reflectora de filtragem de dois milímetros em chumbo e com um aparelho PSC/01. Primeiro tempo de exposição: 1 minuto, $80 \mathrm{Kv}$ 1000MA; segundo tempo de exposição: $1 \mathrm{~m}$ 30s, 1OOKv 1200MA. Filme AGFA Structurix o qual, como se sabe, apresenta uma película emulsionada dos dois lados. A ausência de qualquer imagem sombra indica que estamos perante uma estrutura homogénea integrando um mesmo tipo de material. Não existem vestígios de soldaduras. A ligeira "nuage" de opacidade aos raios X da zona do tacão e anel obtida na segunda exposição de $\operatorname{lm} 30$ s (Foto 3) explica-se pelo facto de estarmos perante as zonas maciças e com maior espessura da peça. 
(por oposição à forma globular da ocarina) e é tapada em campànula numa das extremidades. $\mathrm{O}$ corpo do tubo está dividido transversalmente em três partes distintas, conjugando a representação de elementos do equipamento militar do oficial romano com a organologia do instrumento. Assim, na zona inferior da embocadura, limitada no topo por três finas molduras em relevo, distinguimos a alma ou tacão, a entrada do canal do ar. A decoração intermédia apresenta um friso, limitado por duas finas molduras e quatro linhas de escamas do tipo «lorica squamatta» (ROBINSON, 1975, fig. 442), tudo em relevo, sugerindo a protecção do tronco do militar, e é interrompida pela abertura em semicírculo da boca do instrumento onde o elemento excitador do som - o bisel - ocupa o lábio superior. As escamas das armaduras verdadeiras eram em bronze e estavam ligadas umas às outras com arames. Eram depois cozidas a uma tela de linho por meio de furos centrais. As escamas variavam entre 1 e $5 \mathrm{~cm}$ de comprimento (WATSON, 1969, p. 114-117). A parte superior do tubo, ou reservatório de ar, está decorada com um elmo (cassis) de crista (crista) longitudinal constituída por crina na parte anterior e plumária com duas linhas de penas caindo uma em madeixa sobre a fronte e a outra levantada lembrando o bico adunco duma águia (ROBINSON, 1975, p.140). Penachos semelhantes podem observar-se nas representações de militares na Coluna de Trajano (ROBINSON, p. 182) e na de Marco Aurélio (COULSTON, 1991, fig. 6). O limite inferior do elmo é marcado por uma faixa com linha de pontos em relevo lembrando o sistema de preensão e suspensão das guardas do elmo para a protecção da face e queixo (buccula) (RICH, 1861, p. 86). A execução da peça patenteia formas de grande leveza e equilíbrio próprias do estilo clássico.

Os elmos de centuriões ou de oficiais de patente superior eram ornados de penas ou crinas de cavalo (BERMANI, 1970, p. 132).

Como diz P. Coussin em Les Armes Romaines, p. 438: "Durante os primeiros séculos do Império, o elmo, sem abandonar os tipos itálicos, retoma as formas mais elegantes recebidas outrora dos Gregos. Ao mesmo tempo é enriquecida a decoração. Os sumptuosos elmos, de bronze ou de ferro, mas revestidos de latão, prata ou ouro, dão uma ideia do luxo de algumas armas desta época. Os penachos, cada vez mais altos à medida que o tempo passa, tornam-se um uso cada vez mais frequente" (LAVEDAN, 1931).

O comprimento total do apito de que aqui tratamos é de $28,1 \mathrm{~mm}$, compreendendo a embocadura $(9,9 \mathrm{~mm})$, o corpo do tubo $(15,3 \mathrm{~mm})$ 
e o penacho $(2,9 \mathrm{~mm})$. O diâmetro interno da embocadura corresponde ao diâmetro interno do corpo do tubo $(8,1 \mathrm{~mm})$. A altura da secção do canal do ar é de 1,5 mm. Estas são as medidas com as quais se identificam, actualmente, os tubos dos orgãos (SimõEs, 1995).

$\mathrm{O}$ anel de suspensão, de aro fechado circular, tem secção facetada ou losangonal. Apresenta um diâmetro externo de 20,6 mm e interno de $16,6 \mathrm{~mm}$. E debroado com duas fiadas longitudinais de pontos contínuos em relevo, de um lado e outro do aro, comparável com os pontos do bordo das moedas romanas, especialmente evidentes nos denários republicanos (CRAWFORD, 1970) e alto-imperiais (ROBERTSON, 1962). As linhas exterior e interior contínuas do aro percorrem também a "mesa do anel" e resultam, como já referimos, do escorrimento de metal que passou pela zona de encaixe entre as metades do molde. A protuberância da linha exterior do anel indicia a presença de um jito de ligação a outros moldes, num processo de fabrico em série, ou uma abertura para a saída do ar do molde a fim de obter uma melhor fundição.

A peça pesa 9,14 g. Está em condições de poder ser utilizada e é bom o seu estado de conservação $\left({ }^{7}\right)$.

\section{Usos e sonoridades}

Chama-se apito a qualquer instrumento que, pelo atrito do fluido que o atravessa, produza silvo.

A palavra apitar tem uma origem onomatopaica, como ribombar ou pipilar, por imitação do repetido do som. Aparece-nos nos textos apenas a partir do século XVI. A palavra latina usada para o referir era sibilare e o instrumento ou apito produtor do silvo, sibilus. Esta palavra é usada nos textos antigos quando os autores se referem ao silvo acasalador da serpente, ao incómodo temor do seu som ou ao assobio dos lábios (GAFFIot, 1934, p. 1436). Ovídio usa a palavra Fistula (tubo ou flauta de Pan) para designar um instrumento com o qual se pode produzir um Sibilum (Ovid. 15. Met. 785).

(7) Jochen Garbsch ilustrou o seu artigo That's Entertainement: Musiker und Tänzer (1994, p. 298) com duas fíbulas preparadas também para serem usadas como apitos.

Conimbriga, 36 (1997) 165-175 
Estamos perante um instrumento de época portador de uma sonoridade fidedigna $\left(^{8}\right)$.

A vibração sonora deste instrumento apresenta um timbre metálico característico. O silvo obtido é estridente e quanto mais insistente, mais impertinente. Soprado forte, emite um som muito agudo, perturbante, tanto mais incómodo quanto mais repetido. Quase ultrapassa o espectro sonoro audível já perto dos ultra-sons. A nota obtida - C \# 5 é uma extensão do dó sustenido lembrando o timbre dos tiples e flautins das fanfarras. A altura do som (frequência de vibração das ondas sonoras) é de $2200 \mathrm{~Hz}$ ultrapassando largamente a capacidade de emissão de agudos na voz humana que é de $1056 \mathrm{~Hz}$ (SA, 1993, p. 241). É possível ouvir o seu som emitido a kilómetros de distância. Com aquele timbre, tocado forte e com a altura que lhe foi tecnicamente introduzida obtém-se deste instrumento um som "fero" apropriado para a transmissão de ordens de comando. E possível emitir com ele dezenas de diferentes sinais sonoros conjugando a emissão de notas longas e curtas com variações (rufado ou picado por ex.) à semelhança do que se usa hoje para transmitir o abecedário em Morse, no montanhismo, ou as ordens na Marinha. As diversões, bem como as cerimónias civis, religiosas ou militares, têm na maioria dos casos um apoio em material sonoro importante e rico proporcionando a mediatização de mensagens específicas. Como se sabe, as legiões romanas eram acompanhadas por uma guarnição de 100 músicos militares, os aenatores, compreendendo trombeteiros de três espécies: tubicines, bucinatores et cornicines (BUCHNER, 1980, p. 54-55). Para além das cerimónias e manobras militares, actuavam como bandas para entretenimento das tropas. Para as sessões de treino dos manípulos, das centúrias ou das secções de oito homens, seriam usados, muito possivelmente, para além da voz, sistemas sonoros mais versáteis e menos ostensivos do que as trombetas, essas sim indispensáveis para dar o sinal de ataque e retirada.

Serviria o apito de chumbo aqui apresentado para a transmissão de ordens de comando ou era apenas usado como instrumento de sinal?

$\left.{ }^{8}\right) \quad$ Através da emissão de notas curtas, extensas, rufadas, picadas e variando as suas ligações é possível transmitir, com as gradações rítmicas deste instrumento, dezenas de sinais sonoros que, estabelecida a sua codificação, podiam servir, por exemplo numa organização militar, para a chamada de pessoal, indicação do tipo de manobras, material necessário, definição de locais, ordem unida e sinais gerais que vão do toque de alvorada ao silêncio, faina geral e honras militares como na Armada dos nossos dias. 
Seria usado, dado tratar-se de um objecto artístico, como um valor próximo duma condecoração como os conhecidos torques, armillae, phalerae, hasta pura, vexillum et coronael (WATSON, 1969, p. 114-117). Tratar-se-á de uma produção em série, que seria de uso generalizado por parte dos militares com patente superior? Tratar-se-á, como os anéis de ouro, de uma insíginia de nobreza, uma recompensa ou um privilégio inerente a certas funções? (FrANÇA, 1989, p. 17-64).

Os chefes militares estavam autorizados a conferir ornamentos Ocorniculum) como marca de distinção aos soldados que em seu entender o mereciam (RICH, 1861, p. 192). Estaremos, neste caso, perante o reconhecimento duma distinção?

Será este apito um elemento identificador de determinada cohors urbana ou tratar-se-á de um nobre apetrecho de comunicação na caça? Seria um implemento dos efectivos da polícia urbana?

Bem-haja ao Senhor António Geada Simões Rito de Condeixa-a-Nova que achou e tão seguramente guardou esta pequena peça do nosso Património. Bem-haja a quem contribuiu, duma forma ou outra, e tornou possível este estudo.

\section{BIBLIOGRAFIA}

AlARCÃo, Jorge de, 1988, Introdução ao Estudo da História e Património Locais, "Cadernos de Arqueologia e Arte", 2, Instituto de Arqueologia da Faculdade de Letras, Uni. Coimbra.

AlARCÃo, Jorge de, et alii, 1977, L' Architecture, "Fouilles de Conimbriga", 1, Paris.

Bellido, Antonio Garcia, 1970, Problemas sociociales del urbanismo en el area mediterranea durante la edad antigua, "XIII Congresso Internacional de Ciências Históricas", Moscovo.

Bermani, Maria Felice, Camusso, Lorenzo, Facchi, Paolo, 1970, Os Milénios, 2, Verbo, Lisboa.

BERnFeld, Dan, 1993/1, Valorisation de l'espace et de sa Dimension Culturelle: les dommages de la construction dispersée, Ilème Colloque européen EUROCULTURES, CCRC, Coimbra, p.33-44.

Bernfeld, Dan, 1993/2, Le musée «participé», "Museum”, 179, Unesco, Paris.

BuCHNER, Alexander, 1980, Colour Encyclopedia of Musical Instruments, Hamlyn, London.

Coulston, J. C. N., 1991, The "Draco" Standard, "Journal of Roman Military Equipment Studies", 2.

Crawford, Michael H., 1974. Roman Republican Coinage, Cambridge University Press. 
Evin, Jacques, et Allii, 1990, Les Mystères de l'Archéologie - Les Sciences à la Recherche du Passé, "Caisse National des Monuments Historiques et des Sites", Presses Universitaires de Lyon.

FrançA, E. Ávila, 1969, Anéis, braceletes e brincos de Conimbriga, "Conimbriga", 8, p. 17-64.

GafFlot, Felix, Dictionnaire Illustré Latin Français, "Hachette”, Paris, 1934.

GaRBsch, Jochen, That's entertainement: Musiker und Tänzer, "Römicher Alltag in Bayern", München, 1994.

Grant, Michael, 1974, The Army of the Caesars, Weidenfeld and Nicolson, London.

Hours, Juliette Liszak, LAHANIER, Christian, 1980, Métal, "La vie mystérieuse des chefs d'oeuvre. La science au service de l'art", Editions de la Réunion des Musées Nationaux, Paris.

Laranjeira, M. F. et Fronteira E Silva, M. E., 1968, Isotopic Analyses of Roman Lead from Conimbriga and of galenas from neighbouring mines, "Revista Portuguesa de Química”, 10, p. 55-56)

Laved AN, Pierre, 1931, Dictionnaire Illustré de la Mythologie et des Antiquités Grecques et Romaines, Librairie Hachette, Paris.

Marinho, José, 1974, Monnaies Arabes, "Fouilles de Conimbriga", 3, Appendice, I, Paris.

Moutinho AlarcãO, Adilia, 1994, Colecções do Museu Monográfico de Conimbriga, IPM, Lisboa.

Oleiro, J. M. Bairrão, 1952, Conimbriga e alguns dos seus problemas, "Humanitas", 4, p. 32-42.

Patrício, Isabel, 1995, Urbanismo e Violência. Pensar a Cidade, "Revista Olhares", 2, (Lisboa).

Perrot, Jean, 1971, The Organ from its Invention in the Hellenistic Period to the end of the Thirteenth Century, Oxford University Press, London.

PessoA, Miguel, 1986, Subsídios para a Carta Arqueológica do Período Romano na Área de Conimbriga, "Conimbriga", 26, (Coimbra).

Pessoa, Miguel, Madeira, José Luís, Ferreira, Delfim, 1991, A Muralha Augustana de Conimbriga - Elementos de Estudo, Condeixa.

Pessoa, Rodrigo, M. L. et alii, 1994, Percursos de Sonho e Práticas na Valorização da Memória de Todos, "Associação Ecomuseu Condeixa, Arzila, Rabaçal, Penela".

Rich, Antony, 1861, Dictionaire des Antiquités Romaines et Grecques, Paris.

Rich, Antony, 1861, Dictionaire des Antiquités Romaines et Grecques, Paris.

Robertson, Anne S., 1962, Roman Imperial Coins in the Hunter Coin Cabinet: I. Augustus to Nerva, "Oxford University Press", London.

Robinson, H. Russel, 1975, The Army of Imperial Rome, Arms and Armour Press, London.

SÁ, Carlos, 1996, Análise da Composição Elementar de um Apito Anelar Romano de Conimbriga através das Técnicas de Microscopia Electrónica de Varrimento e de Microanálise de Raios X - SEM/EDS, Centro de Estudos de Materiais da Universidade do Porto.

SÁ, Maria Teresa Marques, 1993, Física do 12. Ano, “Texto Editora”, Lisboa. 
SimÕES, António, 1995, Órgãos de Portugal - Zona Centro, Secretaria de Estado da Cultura/Delegação da Zona Centro, Coimbra.

SouzA, Vasco de, 1990, Portugal: Corpus Signorum Imperii Romani Corpus der Skulpturen der Römischen Welt, Instituto de Arqueologia da Fac. de Letras, Coimbra.

Watson, G.R., 1969, The Roman Soldier, "Thames and Hudson”, London.

WeBster, Graham, 1969, The Roman Imperial Army of the First and Second Centuries A. D., Adam and Charles Black, London.

\section{Agradecimentos}

Doutor Jorge de Alarcão (Fac. Letras Uni. Coimbra), Doutor José Ribeiro Ferreira (Fac. Letras Uni. Coimbra), Doutor Carlos Sá (Fac. Ciências Uni. Porto), Prof. António Simões (Organeiro), Dr. Lino Rodrigo (Antropólogo da C.M.L.), Miguel Bandeira Pessoa (Estudante da F.C.T.U.C.), Dra. Conceição Barata (Técnica Superior da C.M.L.), Fotógrafo António Pinto (Instituto da Juventude de Coimbra), Fotógrafo Delfim Ferreira (Estúdios Lousã), Dr. José Luís Madeira (Técnico Superior do Instituto de Arqueologia da Fac. de Letras da Univ. de Coimbra), Fotógrafo Manuel José Palma (Instituto José de Figueiredo de Lisboa), Ecomuseu e Câmara Municipal de Condeixa. 


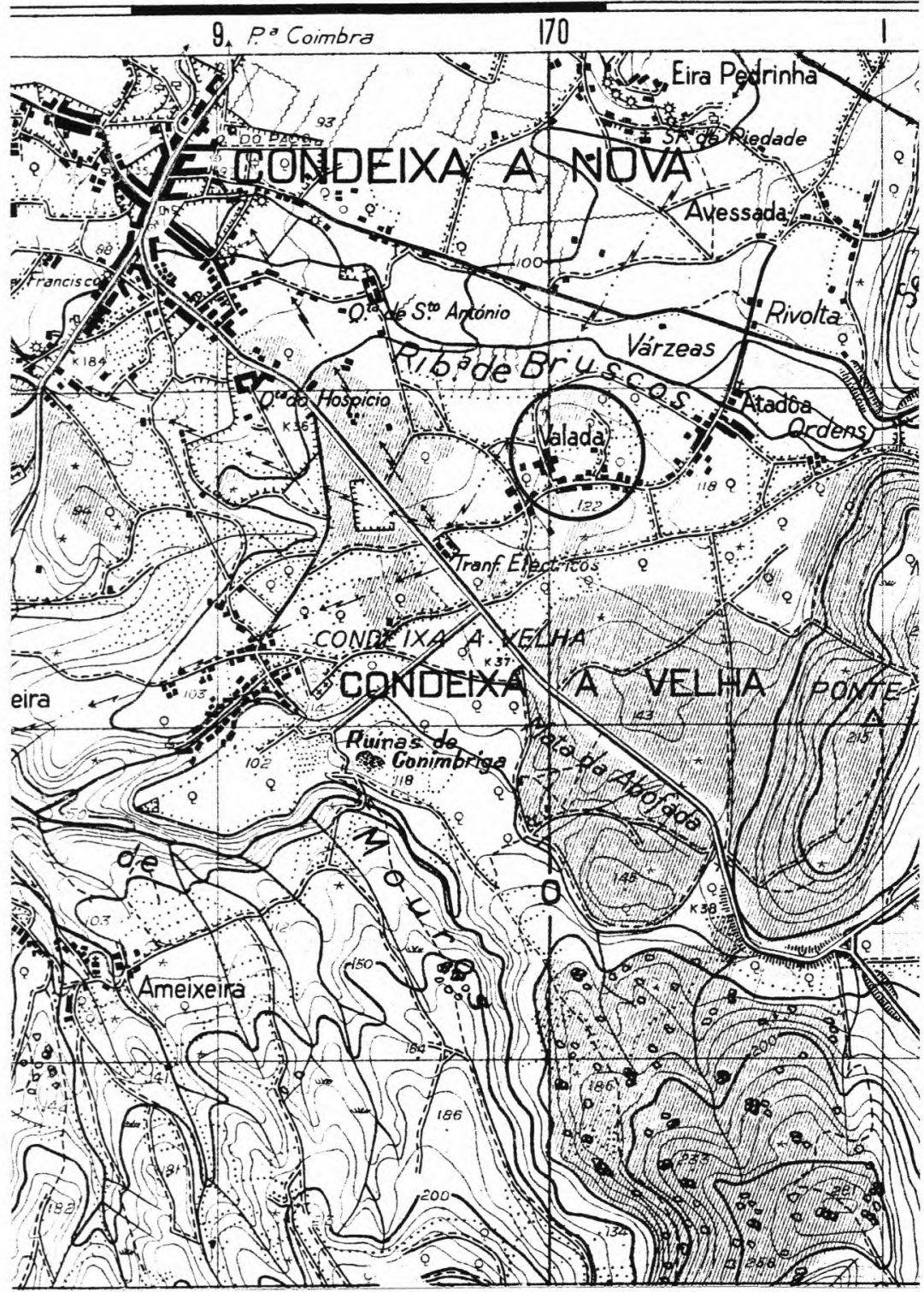

EsT. I - Localização de Conimbriga e do aglomerado de Valada na Carta Militar 1:25.000. Folha 251. Serviços Cartográficos do Exército, 1947. 


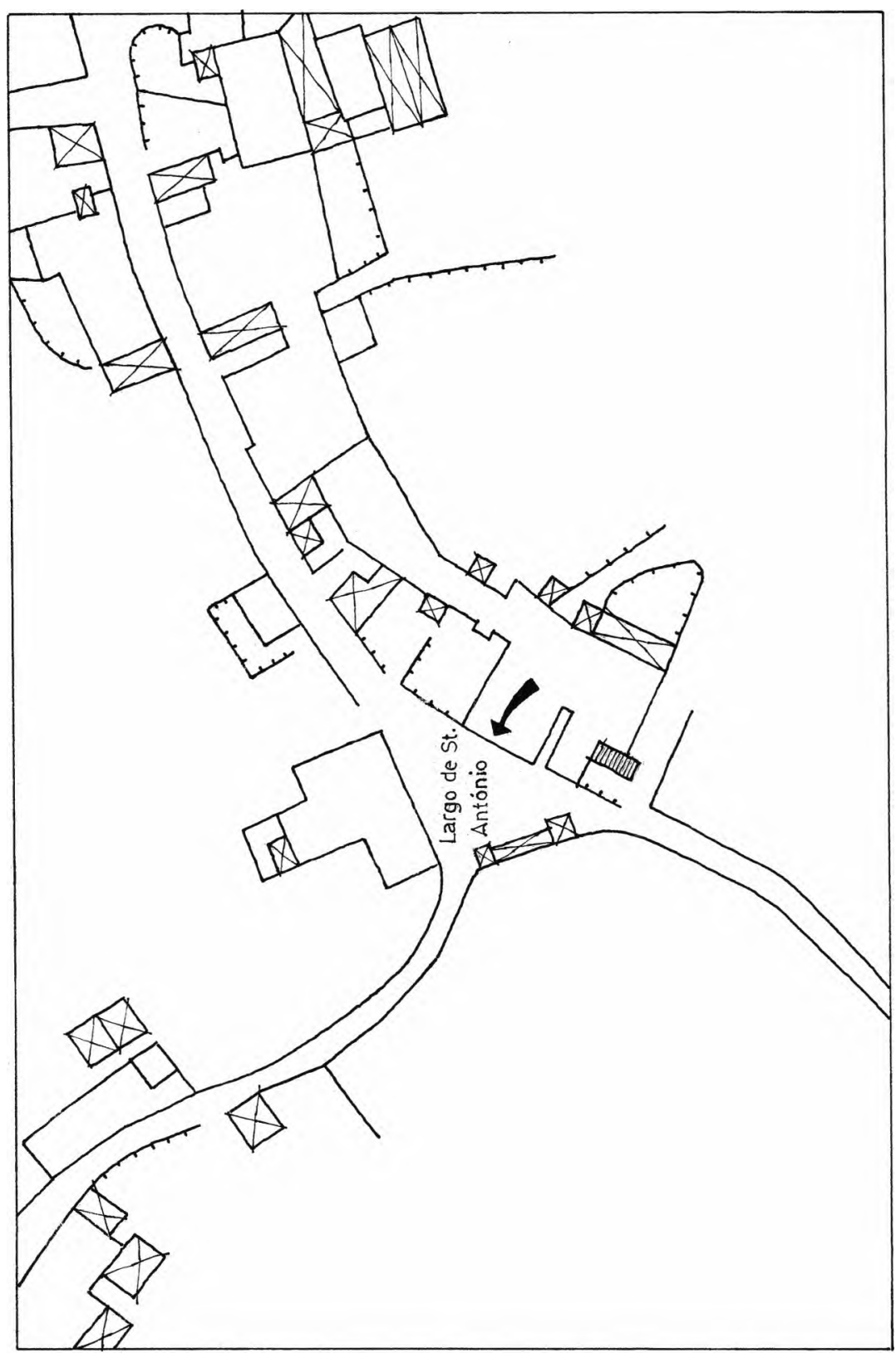

EsT. II - Planta de pormenor do Largo de Santo António, com indicação do local do achado a partir da planta topográfica da EDP de 1960. Escala 1:1000. 


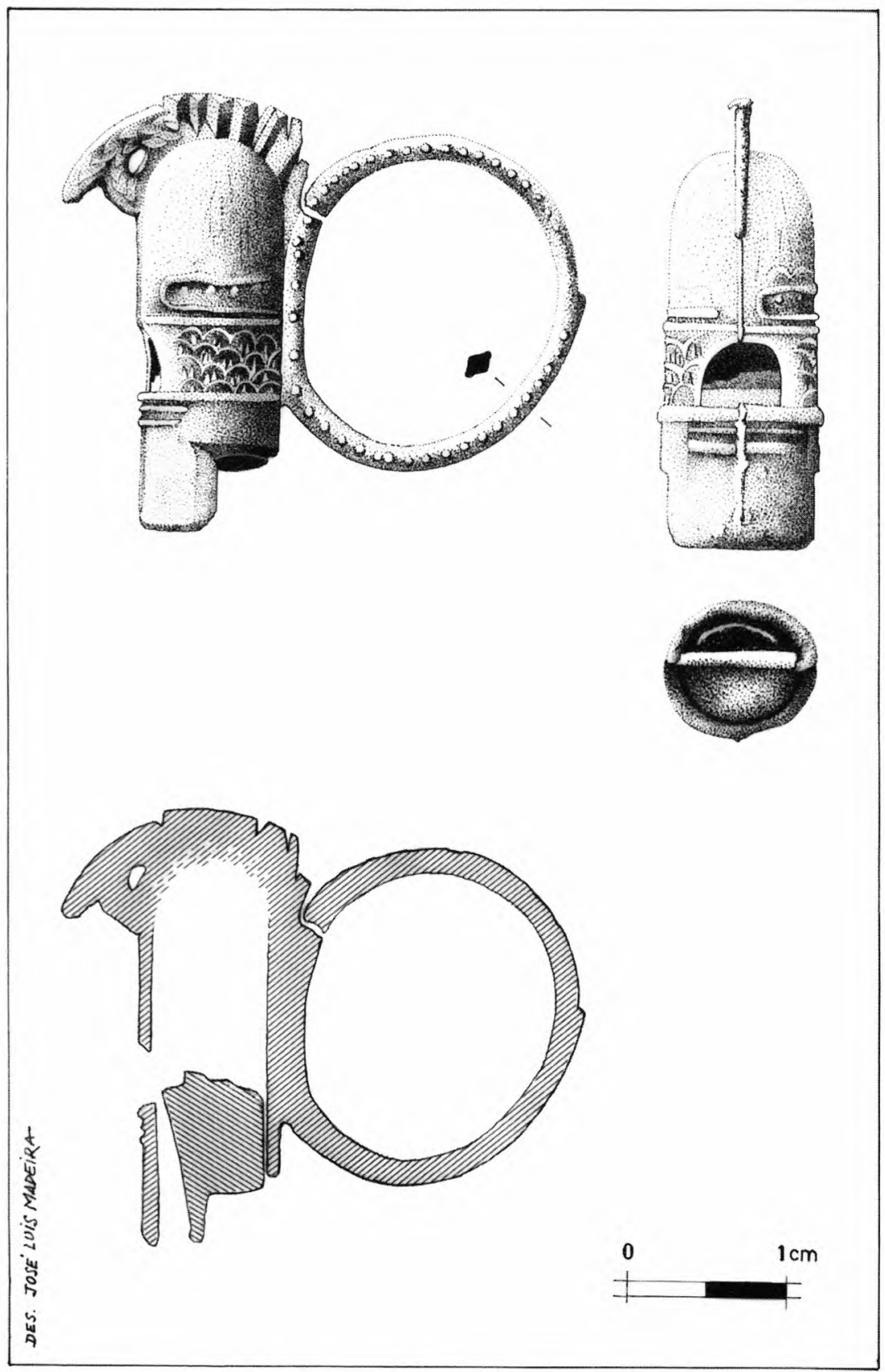

EsT. Ill - Apito anelar: vista de perfil, frente, secção e canal do ar da embocadura. 


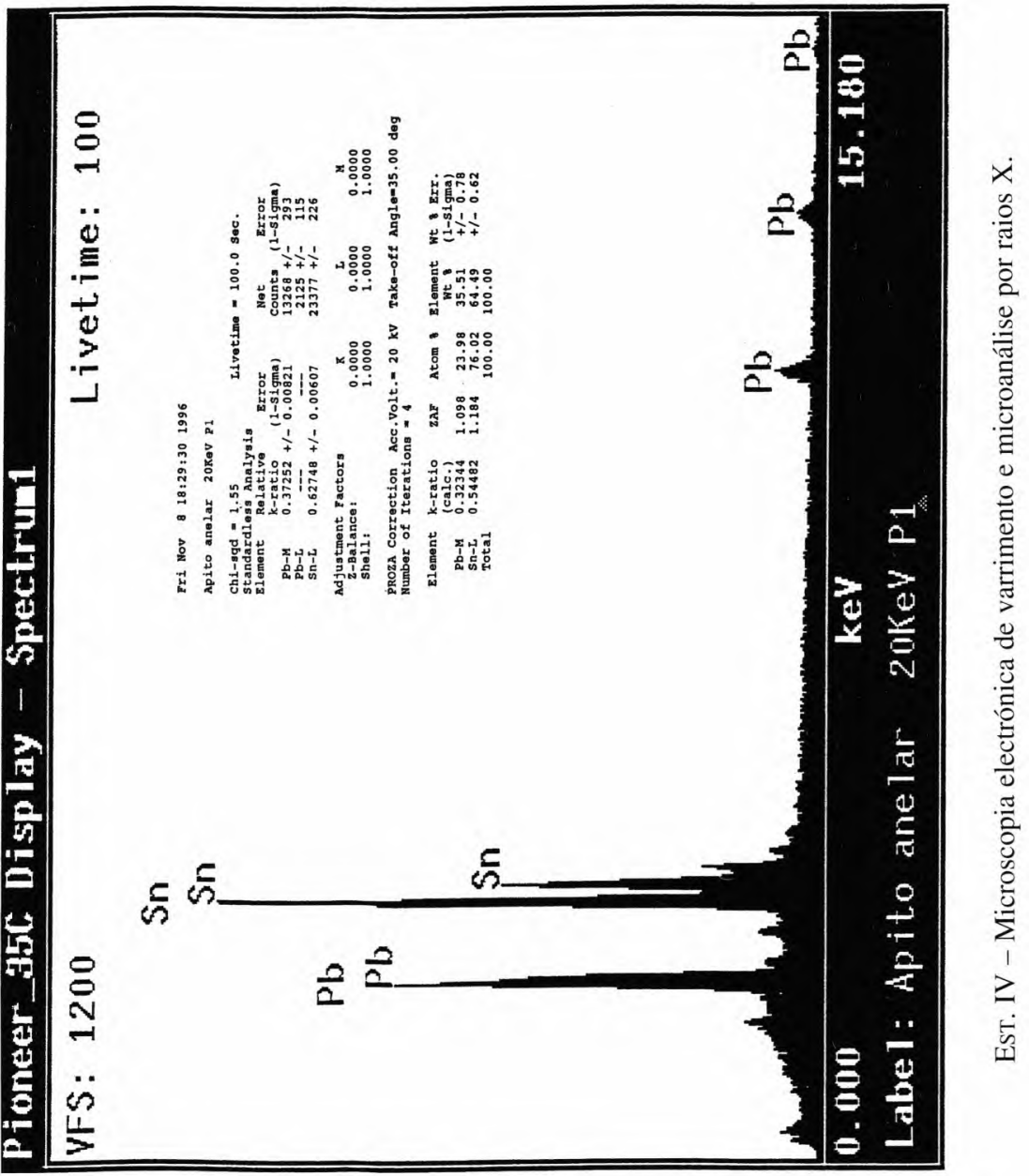




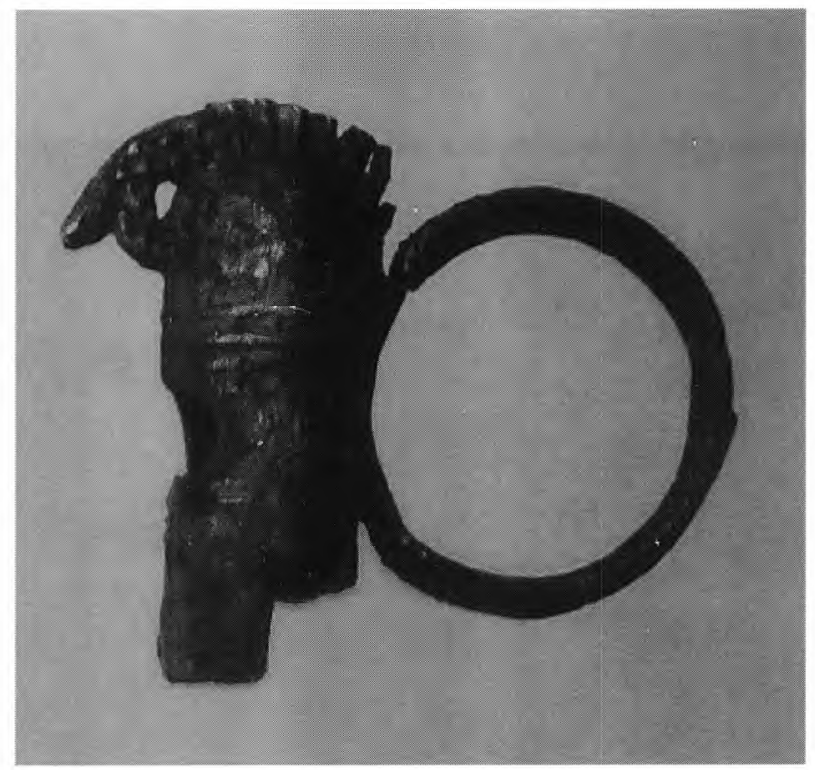

Fото 1 - Apito anelar. Vista de lado.

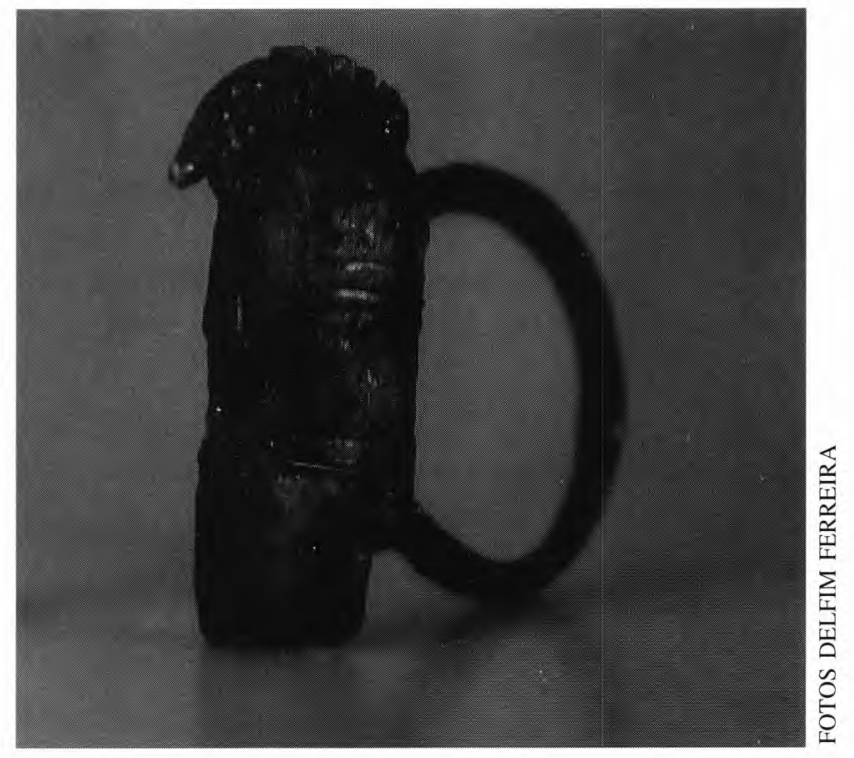

Fото 2 - Idem. Vista a três quartos. 


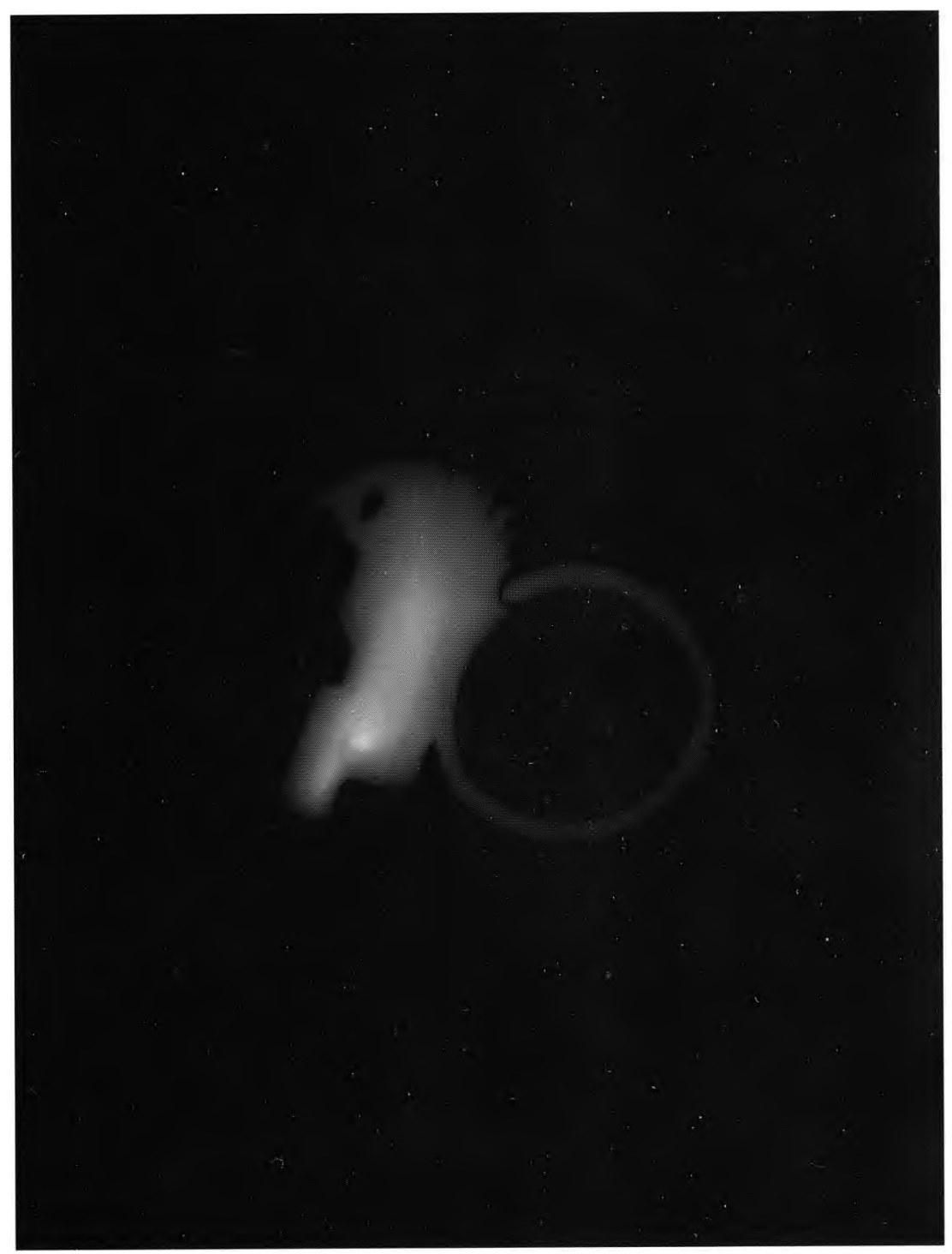

Foto 3 - Chapa de Raio X n. ${ }^{\circ} 2$ - Tempo de exposição: $1 \mathrm{~m} 30 \mathrm{~s}, 100 \mathrm{Kv} 1200 \mathrm{MA}$. 